\title{
Qualidade bacteriológica do leite pasteurizado tipo C produzido no estado do Rio de Janeiro
}

\section{Bacteriological quality of pasteurized type C milk produced in the State of Rio de Janeiro}

\author{
Silvia Maria Lopes Bricio, ${ }^{*}$ Cláudia Guerreiro da Silva, ${ }^{*}$ Regina Maria Finger*
}

\begin{abstract}
Resumo
Foram analisadas 45 amostras de leite pasteurizado tipo $\mathrm{C}$ processado pelos laticínios do estado do Rio de Janeiro, no período de janeiro a dezembro de 2001. As amostras chegaram ao laboratório diretamente dos lacticínios do interior do estado do Rio de Janeiro, colhidas pelo Serviço de Inspeção Federal do Ministério da Agricultura. As análises de coliformes totais e fecais, Contagem de Bactérias Heterotróficas Aeróbias Mesófilas (CBHAM) e pesquisa de Salmonella foram realizadas no Laboratório Analítico de Alimentos e Bebidas pertencente ao convênio MAPA/UFRRJ. Os resultados foram comparados com os padrões microbiológicos do regulamento técnico de identidade e qualidade de leite pasteurizado do Ministério da Agricultura (BRASIL, 1999). Estavam fora do padrão, 4,4\% das amostras analisadas para a contagem de BHAM, 24,4\% para enumeração de coliformes totais e $11,1 \%$ para coliformes fecais. Não foi encontrada Salmonella em nenhuma das amostras analisadas. Os resultados encontrados indicam uma provável falha no tratamento térmico ou contaminação do produto antes ou durante o envase, sendo necessária uma avaliação do processamento para determinar o foco do problema e evitar que a população consuma leite de má qualidade.
\end{abstract}

Palavras-chave: leite pasteurizado, qualidade microbiológica, laticínios.

\begin{abstract}
Forty-five samples of pasteurized type $C$ milk processed by the creamary plant from the state of Rio de Janeiro - Brazil was analyzed throughout January to December of 2001. The samples were colleted by the Inspection Service of Brazilian Ministery of Agriculture. The analysis was conducted at the Maracanã Laboratory in Rio de Janeiro - Brazil, managed by the Universidade Federal Rural do Rio de Janeiro and Ministery of Agriculture. The results were compared with microbiologic standards of quality and identity of pasteurized milk determined by Agricultural Agency (BRASIL, 1999). The data shown that $4.4 \%$ of analysed samples for heterotrophic mesophilic aerobic bacteria, $24.4 \%$ analysed total coliforms bacteria and $11.1 \%$ of fecal coliforms did not comply with Brazilian standards. Salmonella was not detected in any of the analyzed samples. These results indicate a probably imperfection in the thermal treatment of milk or by contamination of the product before and or during packing procedure. There is a need of an evaluation of the milk processing to determine the focus of the problem. This may prevent the population from consummates milk of bad quality.
\end{abstract}

Keywords: pasteurized milk, microbiological quality, creamary.

\section{Introdução}

O leite é o produto obtido da ordenha completa e ininterrupta, em condições de higiene, de vacas leiteiras sadias (Brasil, 1999). Possui alto valor nutritivo, e é amplamente consumido pelo homem, sendo considerado um dos principais alimentos da dieta das crianças.

A garantia da qualidade do leite depende de vários fatores nas diferentes etapas da produção e processamento. Deve ser ordenhado a partir de animais sadios, em local higienizado, por pessoal em boas condições de saúde e transportado de forma adequada (Wendpap e Rosa, 1995). Nas usinas, deve sofrer pasteurização e ser mantido sob temperatura máxima de $4^{\circ} \mathrm{C}$ até o transporte; nos pontos de venda a temperatura não pode ser superior a $7^{\circ} \mathrm{C}$ até a entrega ao consumidor (Brasil, 1999).

A pasteurização é um processo térmico que inativa os microrganismos patogênicos associados ao leite, reduzindo os possíveis riscos à saúde humana e provocando mínimas alterações na composição química. Apesar de inativar os patógenos, a pasteurização não recupera um leite de má qualidade, pois permanece uma microbiota em torno de $0,1 \%$ a $0,5 \%$ da quantidade que existia no leite cru antes da pasteurização (Wendpap e Rosa, 1995).

A elevada disponibilidade de nutrientes no leite predispõe esse produto a rápida proliferação de microrganismos contaminantes, tornando-o altamente perecível. Nos últimos

\footnotetext{
* Laboratório Analítico de Alimentos e Bebidas - LAAB convênio UFRRJ/MAPA. Av. Maracanã, 252 - Rio de Janeiro, RJ. e-mail: silviabricio@wnetrj.com.br
} 
anos, tem sido relatada em vários países a ocorrência de surtos de toxinfecções alimentares causadas pelo consumo de leite e derivados contaminados por bactérias patogênicas (Lopes e Stamford, 1997). No Brasil, praticamente não existe levantamento epidemiológico que demonstre a incidência e a gravidade das toxinfecções de origem alimentar, entretanto, trabalhos científicos têm evidenciado a ocorrência de elevado número de amostras de leite pasteurizado fora dos padrões microbiológicos brasileiros (Lopes e Stamford, 1997).

O objetivo deste trabalho foi avaliar a qualidade bacteriológica do leite pasteurizado tipo C produzido no estado do Rio de Janeiro, bem como comparar os resultados com os parâmetros estabelecidos pela legislação brasileira vigente.

\section{Material e métodos}

As análises foram realizadas no Laboratório Analítico de Alimentos e Bebidas pertencente ao convênio existente entre o Ministério da Agricultura Pecuária e Abastecimento e a Universidade Federal Rural do Rio de Janeiro. O período abrangido foi de janeiro a dezembro de 2001. As amostras chegaram ao laboratório diretamente dos lacticínios do interior do estado do Rio de Janeiro, colhidas pelo Serviço de Inspeção Federal do Ministério da Agricultura, e transportadas ao laboratório em recipientes de isopor com gelo. Foram analisadas 45 amostras para coliformes totais e fecais, CBHAM e pesquisa de Salmonella.

A metodologia empregada foi a recomendada pelo Manual de Métodos de Análise Microbiológica de Alimentos do Ministério da Agricultura (BRASIL, 1991). Para a determinação de coliformes totais foi utilizada a técnica do Número Mais Provável (NMP), com três séries de três tubos de caldo Lauril Sulfato Triptose incubado a $35^{\circ} \mathrm{C}$ por 48 horas para a prova presuntiva, e para a prova confirmativa utilizou-se o caldo Verde Brilhante Bile $2 \%$ lactose incubado a $35^{\circ} \mathrm{C}$ por $24 / 48$ horas. Para coliformes fecais utilizou-se o caldo EC, incubado a $45+/-0,2^{\circ} \mathrm{C}$ por 48 horas em banho-maria com agitação. Para a contagem de bactérias heterotróficas aeróbias mesófilas, foi utilizado o método de semeadura em profundidade utilizando o Agar Padrão para contagem com incubação a $35^{\circ} \mathrm{C}$ por 48 horas. Foram selecionadas placas entre 25 e 250 UFC. No pré-enriquecimento da pesquisa de Salmonella, em 25 $\mathrm{mL}$ : da amostra foram adicionados $225 \mathrm{~mL}$ de água destilada estéril com solução de verde brilhante, para o enriquecimento seletivo foram utilizados os caldos Tetrationato Kauffmann e Selenito Cistina e os meios Agar Xilose Lisina Desoxicolato (XLD) e Agar Entérico Hektoen para o plaqueamento seletivo. A triagem foi realizada com os meios TSI e LIA e nas provas bioquímicas foram utilizados: caldo uréia, caldo lisina, caldo malonato-fenilalanina, Agar citrato de Simmons e o meio SIM.

\section{Resultados e discussão}

Nos últimos tempos, têm sido levadas ao público diversas denúncias sobre a qualidade do leite pasteurizado distribuído e destinado ao consumo. Embora alguns pesquisadores questionem os objetivos e a validade de determinadas denúncias, os poucos trabalhos publicados em nosso meio têm evidenciado a ocorrência de elevado número de amostras fora dos padrões microbiológicos legais, tanto em nível de usina de beneficiamento quanto de comércio varejista (Hoffmann et al., 1994, Nascimento, 1982).

Os resultados das análises microbiológicas das 45 amostras de leite pasteurizado tipo C estão apresentados na Tabela 1. Os resultados foram comparados com os padrões microbiológicos do regulamento técnico de identidade e qualidade de leite pasteurizado do Ministério da Agricultura (Brasil, 1999) conforme Tabela 2.

Tabela 1 - Número de amostras de leite pasteurizado tipo C que não atenderam aos padrões microbiológicos do regulamento técnico de identidade e qualidade de leite pasteurizado - MAPA.

\begin{tabular}{c|c|c|c}
\hline Análises & Total & $\begin{array}{c}\text { Número de amostras } \\
\text { fora do padrão }\end{array}$ & $\%$ \\
\hline Contagem de BHAM & 45 & 2 & 4.4 \\
\hline NMP de coliformes totais & 45 & 11 & 24.4 \\
\hline NMP de coliformes fecais & 45 & 5 & 11.1 \\
\hline
\end{tabular}

Tabela 2 - Padrões microbiológicos do regulamento técnico de identidade e qualidade de leite pasteurizado - MAPA

\begin{tabular}{c|c}
\hline Microrganismos & $\begin{array}{c}\text { Tolerância para amostra } \\
\text { indicativa }\end{array}$ \\
\hline Contagem de BHAM $(\mathrm{UFC} / \mathrm{mL})$ & $4,0 \times 10^{4}$ \\
\hline Coliformes a $30^{\circ} \mathrm{C}(\mathrm{NMP} / \mathrm{mL})$ & 2 \\
\hline Coliformes a $45^{\circ} \mathrm{C}(\mathrm{NMP} / \mathrm{mL})$ & 1 \\
\hline Salmonella $/ 25 \mathrm{~mL}$ & Ausência \\
\hline
\end{tabular}

Observa-se que do total de 45 amostras, duas (4,4\%) estavam fora do padrão para a contagem de bactérias heterotróficas aeróbias mesófilas, 11 (24,4\%) estavam fora do padrão para coliformes totais e cinco $(11,1 \%)$ estavam fora do padrão para coliformes fecais. Não foi encontrada Salmonella em nenhuma das amostras analisadas.

O grupo de microrganismos coliformes totais é um indicador das condições higiênico-sanitárias da produção e beneficiamento do leite pasteurizado (Barufaldi et al., 1984), além de ser responsável por inúmeras alterações de sabor, aroma e produção de gás.

No presente trabalho, $24,4 \%$ das amostras estavam fora do padrão para coliformes totais. Resultados semelhantes foram encontrados por Gonçalves e Franco (1998) em que $23,3 \%$ das amostras estavam fora do padrão. Estes resultados são superiores aos encontrados por Martins e Albuquerque (1999), Hoffmann et al. (1999) e Nader Filho et al. (1996), em que apenas 12\%, 10\% e 16,25\% das amostras estavam fora do padrão para esse parâmetro respectivamente. Percentuais superiores foram encontrados por Wendpap \& Rosa (1995) e Padilha \& Fernandes (1999) que foram 38,5\% e $32,8 \%$ respectivamente, enquanto que Noleto et al. (1980) encontraram $100 \%$ das amostras fora do padrão para coliformes totais.

Os coliformes fecais são aqueles que fermentam a lactose com produção de ácido e gás a $45^{\circ} \mathrm{C}$ em $24-48$ horas no 
caldo EC. O termo coliforme fecal não tem validade taxonômica, são também chamados de coliformes termotolerantes, sendo esse termo mais adequado do que coliforme fecal. A presença de coliformes fecais no alimento não significa que tenha ocorrido contaminação fecal direta pois eles não são habitantes obrigatórios do trato intestinal. Reservatórios ambientais desses organismos são conhecidos (Kornacki e Johnson, 2001). Nas amostras analisadas foram encontradas cinco $(11,1 \%)$ com coliformes fecais acima dos padrões, estando de acordo com os resultados de Gonçalves e Franco (1998), que encontraram quatro (13,3\%) amostras fora do padrão para o mesmo parâmetro. Nader Filho et al. (1996) e Hoffmann et al. (1999) encontraram quatro (5\%) e cinco $(35,7 \%)$ amostras respectivamente fora do padrão. Wendpap e Rosa (1995) e Martins e Albuquerque (1999) encontraram oito amostras correspondendo a $11 \%$ e $40 \%$ respectivamente fora do padrão, enquanto Padilha e Fernandes (1999) e Noleto et al. (1980) encontraram respectivamente 60 (24\%) e $30(100 \%)$ amostras fora do padrão para coliformes fecais.

O número de bactérias heterotróficas aeróbias mesófilas no leite pasteurizado serve como base para a avaliação da qualidade microbiológica e da conservação, e diretamente sobre o efeito da pasteurização. Sua presença em números elevados indica condições inadequadas de processamento e/ou armazenamento (Wendpap e ROSA, 1995). Foram encontradas duas (4,4\%) amostras fora do padrão para BHAM, o que está de acordo com os resultados de Hoffmann et al. (1999), Wendpap e Rosa (1995) e Gonçalves e Franco (1998) que encontraram respectivamente uma $(12,5 \%)$ e duas $(3 \%)$ e três (10\%) amostras fora do padrão. Na pesquisa realizada

\section{Referências}

BARUFFALDI, R., PENNA, T.C.V., MACHOSHVILI, I.A., ABE, L.E. Condições higiênico-sanitárias do leite tipo "B" vendido na cidade de São Paulo, SP (Brasil), no período de fevereiro a agosto de 1982. Rev. Saúde públ.,São Paulo, v. 18, p. 367-374, 1984.

BRASIL. Ministério da Agricultura Pecuária e Abastecimento. Secretaria de Defesa Agropecuária. Departamento de Defesa Animal. Manual de métodos microbiológicos para alimentos. Coordenação geral de Laboratório Animal. 1991/1992. 2ª revisão, 136 p.

BRASIL. Ministério da Agricultura, Secretaria de Defesa Agropecuária, Regulamento Técnico de Identidade e Qualidade de leite pasteurizado, Portaria nº 56 de 07/12/1999 - DOU 8/12/1999, seção I, Anexo V, p. 42. GONÇALVES, R. M. S.; FRANCO, R. M. Determinação da carga bacteriana em leite pasteurizado tipos "B" e "C", comercializados na cidade do Rio de Janeiro, RJ. Revista Higiene Alimentar, v. 12, n. 53, p. 61-65, 1998.

HOFFMANN, F. L.; GARCIA-CRUZ, C. H.; VINTURIM, T. M. Avaliação das características microbiológicas do leite tipo $\mathrm{C}$ vendido na região de São José do Rio Preto-SP. B. CEPPA, Curitiba, v. 12, n. 1, p. 17-24, 1994.

HOFFMANN, F. L.; GARCIA-CRUZ, C. H.; VINTURIM, T. M.; FAZIO, M. L. $S$. Microbiologia do leite pasteurizado tipo "C", comercializado na região de São José do Rio Preto - SP. Revista Higiene Alimentar, v. 13, n. 65 , p. 51-54, 1999.

KORNACKI, J. L.; JOHNSON, J. L. Enterobacteriaceae, Coliforms and Escherichia colias Quality and Safety indicators. In DOWNES, F. P.; ITO, por Nader Filho et al. (1996) e Martins e Albuquerque (1999) foram encontradas quatro $(5 \%)$ e seis $(30 \%)$ amostras, respectivamente, fora do padrão para esse parâmetro. Resultados superiores foram encontrados por Baruffaldi et al. (1984) e Padilha e Fernandes (1999) em que 26 (65\%) e 31 (12,4\%) amostras, respectivamente, estavam fora do padrão para BHAM. Noleto et al. (1980), analisando trinta amostras, não encontrou nenhuma fora do padrão.

Nos últimos anos foi observado aumento de casos graves de salmonelose em adultos causados pela ingestão de leite cru ou impropriamente pasteurizado, contaminados por Salmonella Dublin (Brasil, 1991). Das 45 amostras analisadas, não foi detectada a presença de Salmonella. Esse resultado está de acordo com os encontrados por Padilha e Fernandes (1999), Wendpap e Rosa (1995) e Noleto et al. (1980). Já os estudos de Martins e Albuquerque (1999) e Hoffmann et al. (1999) encontraram, respectivamente, duas $(10 \%)$ e três $(21,4 \%)$ amostras contendo Salmonella, significando risco para a saúde do consumidor.

\section{Conclusão}

Das 45 amostras analisadas, 24,4\% encontram-se fora dos padrões microbiológicos estabelecidos pelo regulamento técnico de identidade e qualidade de leite pasteurizado do Ministério da Agricultura. Os resultados indicam uma possível falha no tratamento térmico ou recontaminação do produto antes ou durante o envase, sendo necessária uma avaliação do processamento para determinar o foco do problema e evitar que a população consuma leite de má qualidade.

K. Compendium of Methods for the Microbiological Examination of Foods. American Public Healh Association, 4. ed., Cap. 8, p. 69-82, 2001.

LOPES, A. C. S.; STAMFORD, T. L. M. Pontos críticos de controle no fluxograma de beneficiamento do leite pasteurizado. Archivos Latinoamericanos de nutricion, v. 47, n. 4, p. 367-371, 1997.

MARTINS, S. C. S.; ALBUQUERQUE, L. M. B. Qualidade do leite pasteurizado tipo $\mathrm{C}$ comercializado no município de Fortaleza. Bactérias multiresistentes a antibióticos. Revista Higiene Alimentar, v. 13, n. 59, p. 39-42, 1999.

NADER FILHO, A.; AMARAL, A.; ROSSI JUNIOR, O. D.; SCHOECKENITURRINO, R. P. Características microbiológicas do leite pasteurizado tipo $\mathrm{B}$ e $\mathrm{C}$ processado por algumas usinas de beneficiamento do Estado de São Paulo. Revista Higiene Alimentar, v. 10, n. 43, p. 30-32, 1996.

NASCIMENTO, D. Contribuição ao conhecimento das condições bacteriológicas de amostras de leite tipo $C$, antes e após a pasteurização, vendido na cidade de João Pessoa, PB. 1977/78. Faculdade de Ciências Farmacêuticas, USP, 1982 Tese (Doutorado).

NOLETO, A. L. S.; TIBANA, A.;SILVA, C. A. M.; RUBIN, L.; SCHUELLER, S. Análise bacteriológica do leite. An. Microbiol. (Rio de Janeiro), p. 41-51, 1980.

PADILHA, M. R. F.; FERNANDES, Z. F. Avaliação da qualidade higiênico-sanitária do leite tipo "C" comercializado no Recife-PE. Revista Higiene Alimentar, v. 13, n. 61, p. 105-109, 1999.

WENDPAP, L. L.; ROSA, O. O. Qualidade microbiológica do leite pasteurizado tipo C comercializado em Cuiabá - MT. Revista Higiene Alimentar, v. 9, n. 39, p. 11-14, 1995. 